\title{
REVIEWS
}

\section{Management of leg ulcers}

\author{
P K Sarkar, S Ballantyne
}

\begin{abstract}
Leg ulcer is a leading cause of morbidity among older subjects, especially women in the Western world. About 400 years BC, Hippocrates wrote, "In case of an ulcer, it is not expedient to stand, especially if the ulcer be situated on the leg". Hippocrates himself had a leg ulcer. The best treatment of any leg ulcer depends upon the accurate diagnosis and the underlying aetiology. The majority of leg ulcers are due to venous disease and/or arterial disease, but the treatment of the underlying cause is far more important than the choice of dressing. The aetiology, pathogenesis, treatment, and the future trends in the management of the leg ulcers are discussed in this review.

(Postgrad Med F 2000;76:674-682)
\end{abstract}

Keywords: leg ulcers; compression bandages; skin grafting

There are about 400000 patients with leg ulcer disease in the UK and at any one time 100000 have open leg ulcers requiring treatment. This costs about $£ 600$ million/year. ${ }^{1}$ Venous ulceration of the lower leg is the result of increased venous pressure and its secondary effects on the microvascular system. ${ }^{2}$ In patients with venous leg ulcers, nearly half have evidence of a past venous thrombosis while the remainder results from incompetence of valves of the superficial or communicating veins. The venous leg ulcer is an age related disease in the elderly population, especially women. It may be associated with lipodermatosclerosis and eczema. Whereas the venous leg ulcer is usually originated by external trauma, the course is often chronic and/or relapsing.

\section{Epidemiology}

INCIDENCE

Community surveys in Lothian, north west London, and Southampton all suggest an overall incidence of about $0.2 \%$. $^{3}$

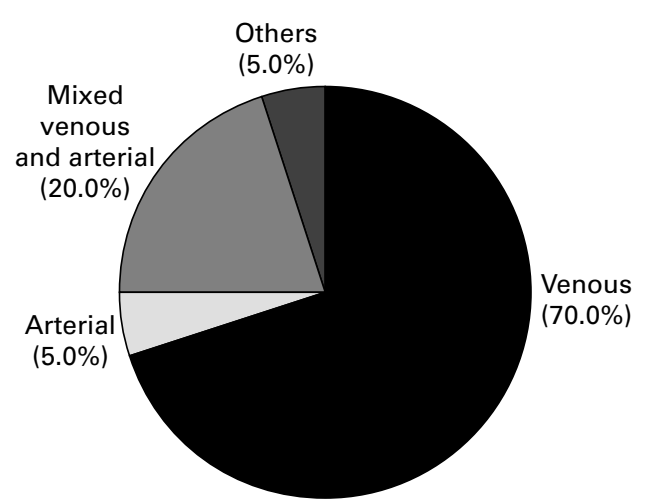

Figure 1 Causes of leg ulcers in the UK (see Moffatt and Franks $^{10}$ and Morrison and Moffatt $\left.{ }^{1 t}\right)$.

\section{PREVALENCE}

The prevalence of leg ulcers in Europe is well documented, varying between $0.18 \%$ and $1 \%$ in different countries. ${ }^{4-7}$ In the UK two major studies demonstrated the prevalence of active ulcers at $0.15 \%$ to $0.18 \%$ in contrast to $1 \%$ in the Scandinavian countries. Leg ulcers occur more commonly in elderly people and their prevalence is likely to increase as the average age of the population increases. ${ }^{89}$

\section{Aetiology}

In the Western world, leg ulcers are mainly caused by venous insufficiency, arterial insufficiency, neuropathy, diabetes, or a combination of these factors (table 1). Venous ulcers are the most common type of leg ulcers, accounting for approximately $70 \%$ of cases (fig 1)..$^{10}$ Arterial disease accounts for another 5\% to $10 \%$ of leg ulcers; most of the others are due to either neuropathy (usually diabetic) or a combination of those diseases. ${ }^{12} 13$

\section{Pathogenesis of venous leg ulcers}

The association between ulceration at the ankle and venous disorders of the lower limbs has been known for more than 2000 years. ${ }^{14}{ }^{15}$ This connection between deep vein damage and ulceration was noted by $\mathrm{Gay}^{16}$ and later by
City Hospital NHS

Trust, Dudley Road, Birmingham B18 7QH, UK

P K Sarkar

S Ballantyne

Correspondence to: Dr Sarkar

Submitted 17 September 1999

Accepted 6 March 2000

\section{Table 1 Causes of leg ulcers}

\begin{tabular}{lllll}
\hline Vascular & Neuropathic & Metabolic & Haematological & Trauma \\
Venous & Diabetes & Diabetes & Sickle cell disease & Pressure \\
Arterial & Tabes & Gout & Cryoglobulinaemia & Injury \\
Mixed & Syringomyelia & Prolidase deficiency & & Burns \\
Tumours & Infection & Panniculitis & Pyoderma & Special \\
Basal cell carcinoma & Bacterial & Necrobiosis lipoidica & Gangrenosum & Hypertensive ulcer \\
Sarcoma & Fungal & Fat necrosis & & \\
Squamous cell carcinoma & Protozoal & & & \\
\hline
\end{tabular}

${ }^{\star}$ Mixed $=$ venous and arterial ulcers. 
Homans, ${ }^{17}$ who also noticed that venous ulcers often had few visible varicose veins.

The concept of venous stasis suggested that stagnant blood lying within tortuous and dilated veins close to the skin can cause tissue anoxia and cell death. Recently, it has been proposed that the preceding stage of venous ulceration represents a scleroderma-like skin called lipodermatosclerosis. ${ }^{18}$ There is a growing recognition that an excessive proteolytic activity by proteases, especially that of matrix metalloproteinases (MMP1, MMP2, MMP8, and MMP9) ${ }^{19}$ and fibrinolytic factors of the plasminogen activation system may be a key feature in the pathogenesis of venous leg ulceration. Elevated expression on mRNA and protein level of MMPs and fibrinolytic factors have been detected in liposclerotic skin lesions. ${ }^{18}$ Furthermore, MMP2 was imbalanced by locally reduced expression of tissue inhibitors of metalloproteinases (TIMP2) in the basement membrane zone of skin lesions. ${ }^{19}$ MMP8 is the predominant collagenase in healing wounds and non-healing ulcers. ${ }^{20}$ But in diabetic foot ulcers, increased nitric oxide synthase activity may be responsible for the impaired healing. ${ }^{21}$ Furthermore, the increased activity of arginase could account for the characteristic callus formation around the ulcers. In addition, the lower concentrations of transforming growth factor- $\beta 1$ in diabetic ulcers may explain the raised concentrations of nitric oxide in this condition. ${ }^{21}$

Loots and colleagues demonstrated the important differances in cellular infiltrates and extracellular matrix of chronic diabetic and venous ulcers compared with acute wounds. ${ }^{22}$ The CD4/CD8 ratio in chronic ulcers was significantly lower $(p<0.0027)$ due to a relatively lower number of CD4+T cells. There was a significantly higher number of macrophages in the edges of both types of ulcers. ${ }^{22}$

Hahn et al found that the upregulation of endothelial adhesion molecules (ICAM-1) and dermal infiltration by T-lymphocytes and macrophages in chronic venous insufficiency patients is limited to the region of the ulcer, or at least to skin areas with a severe microangiopathy, and is part of a secondary elimination of necrotic tissue (an "injury and repair" process). ${ }^{23}$

In patients with venous disease, there is incompetence of the valves within the perforating veins connecting the superficial to the deep venous systems in the leg. In normal subjects, venous pressure decreases during exercise. In patients with venous incompetence, pressure remains high during exertion. ${ }^{24}$ High venous pressure is associated with capillary proliferation and increased permeability of large molecules into the skin. ${ }^{24}{ }^{25}$ It is not clear how venous hypertension is transmitted into skin ulceration, but it is apparent that venous ulcers represent a disease of the cutaneous microcirculation as there is rarefaction and dilatation of the skin capillaries (atrophie blanche) together with the changes in the microlymphatics. ${ }^{26}$ In 1982, Browse and Burnand proposed that the high ambulatory venous pressure within the calf muscle is transmitted to the capillary circulation in the skin and subcutaneous tissues of the calf. ${ }^{15}$ They hypothesised that the distended local capillary bed widened the endothelial pores, allowing fibrinogen molecules to escape into the extracellular fluid, where they form fibrin complexes around the capillaries. $^{27}$ Pericapillary fibrin has been shown to impede oxygen diffusion in the patients with venous disease. ${ }^{28}$

Various theories have been put forward-for example, venous stagnation, fibrin cuff, white cell trapping, and growth factor trapping theories. In the "venous stagnation" theory, blood stagnates within the veins leading to local ischaemia and ulceration. The "fibrin cuff" theory states that increased venous pressure causes leakage of macromolecules from plasma into perivascular space when fibrinogen changed to fibrin and this acts as a barrier to diffusion of oxygen and nutrients. ${ }^{26}$ It is now recognised that the fibrin cuff is seen as an effect but not a cause of the disease, as these lesions are seen in many other chronic wound situations. Pericapillary fibrin cuffs remain a prominent feature, whether they act as a barrier, a marker for endothelial cell damage, or as part of an overall mechanism of macromolecular leakage and trapping. ${ }^{29}$

A recent hypothesis proposed that in venous ulceration, trapped leucocytes occlude capillaries, thereby resulting in cutaneous ischaemia. ${ }^{30}$ White cells are normally trapped within the cutaneous microcirculation when legs are dependent. In venous hypertension, these white cells are activated leading to damage and destruction of the capillaries. ${ }^{31}$ Falanga and Eaglstein have proposed that macromolecules leaking into the dermis "trap" growth factors and matrix material leading to inadequate tissue repair, which eventually causes ulceration..$^{32}$

The skin may break down, due to three mechanisms: (a) damage to blood vessels leading to ischaemia, (b) inflammation, and/or (c) infiltration. In many instances, it is the inability of the damaged skin to repair itself normally that results in ulceration. ${ }^{26}$

Similar to fibrin cuff theory, growth factors and cytokines are held in the fibrin cuff preventing the maintenance of the normal homoeostatic environment.

More recently, Birgette Maessen-Visch and colleagues claimed that factor V Leiden mutation is more frequent in patients with venous leg ulceration than in the control group and the general population. Patients with factor V Leiden mutation have an increased risk of developing deep vein thrombosis and recurrent leg ulceration. ${ }^{33}$

Danielsen et al demonstrated that the exotoxin A serum antibodies in patients with chronic leg ulcers, infected with Pseudomonas aeruginosa, may provide a marker for ulcer deterioration, and may support the decision for skin grafting. ${ }^{34}$

There are many predisposing factors, which may prevent healing of leg ulcers, shown in table 2 . 
Pathogenesis of arterial (ischaemic) ulceration

Arterial or arteriolar occlusion due to any cause can result in ischaemia of the skin and subcutaneous tissues which might lead to ulceration. Peripheral vascular disease due to atherosclerosis, diabetes with microvascular or macrovascular disease and/or vasculitis could lead to ischaemic leg resulting in ulceration. ${ }^{35}$

There are three mechanisms involved in the pathophysiology of ischaemic leg ulcer ${ }^{35}$ :

(1) Extramural strangulation

(2) Mural thickening or accretion

(3) Intramural restriction of blood flow

Extramural strangulation is usually due to scar tissue and radiodermatitis causing fibrotic bands around the arterioles which may give rise to small but persistent ischaemic ulceration. Mural thickening or accretion of intimal plaques as for example in atherosclerosis, may proceed with an impaired blood flow until atherothrombosis, embolism, or superimposed infection may precipitate complete occlusion, resulting in ulceration. Intramural changes could occlude the small vessels by changes in blood viscosity, platelet adhesiveness and/or fibrinogenesis as in vasculitis, which might lead to leg ulceration.

There is often considerable overlap and the exact pathogenesis cannot be always well defined. Most acute forms of vasculitis and some subacute and chronic forms are likely to cause leg ulceration due to tissue hypoxia and exudation of fibrin-like substances. ${ }^{35}$

\section{Diabetic foot ulcer}

There is usually small vessel disease which interferes with peripheral circulation leading to tissue hypoxia, which may result in ulceration after minor or major trauma. Peripheral gangrene may occur as a large single ulcer characteristically situated at the side or at the back of the ankle due to atherosclerosis. Peripheral neuropathy may coexist, with cold, swollen, and dry feet. Trivial trauma or blister due to any cause may lead to ulceration. ${ }^{36}$

\section{Haematological disorders}

Indolent, non-healing ulcers are a feature of sickle cell disease, ${ }^{37}$ thalassaemia, and other haemolytic anaemias. These are usually due to blockage of microcirculation. Thrombotic and occlusive diseases-for example, antiphospholipid syndrome, protein $\mathrm{C}$ and protein $\mathrm{S}$ deficiency, cryoglobulinaemia, etc, lead to rapid skin necrosis and gangrene. ${ }^{26}$

Familial leg ulcers caused by genetic disorders of coagulation, causing recurrent familial venous thrombosis, may occur as a result of

Table 2 Factors which may prevent healing of leg ulcers

\begin{tabular}{ll}
\hline Oedema & $\begin{array}{l}\text { Congestive cardiac failure } \\
\text { Postural/gravitional oedema } \\
\text { Reduced mobility }\end{array}$ \\
Arthritis & Increased risk of lymphoedema \\
Skin disease & Eczema \\
Systemic disease & Diabetes mellitus \\
Nutritional & Vitamin C deficiency \\
Drugs & Corticosteroids/immunosuppressives \\
Exercise & Lack of physical activity \\
Psychosocial & Depression/loss of interest in healing \\
\hline
\end{tabular}

mutations in protein $\mathrm{C}$, protein $\mathrm{S}$, antithrombin III, fibrinogen, and factor V genes. $^{38} 39$

\section{Infections}

Infections may lead to ulceration that is often slow in healing because of associated oedema, cellulitis, thrombophlebitis, or underlying vascular disease or diabetes. Bacterial synergistic gangrene (Meleney's ulcer) extends rapidly and usually has a burrowing, bluish, and undermined edge. ${ }^{35}$ Primary uncomplicated streptococcal ulcer is rare, but Streptococcus pyogenes or Staphylococcus aureus may complicate existing ulceration. Tuberculous cutaneous ulcer might occur in erythema induratum or Bazin's disease, situated usually on the back of the calves. ${ }^{35}$

\section{Hypertensive ulcer Synonymous Martorell's ulcer)}

In hypertension, the density of the capillary beds in the middle and deep dermis of the skin particularly of its lateral aspect is much reduced, which may predispose to ischaemic necrosis when the sparse arterioles are subjected to severe hypertension. ${ }^{35}$ Hypertension produces superficial ulceration, ${ }^{26}$ when peripheral pulses are always present, distinguishing the condition from peripheral vascular disease.

\section{Rheumatoid arthritis/vasculitis}

The leg ulcer usually develops on the shin or ankle after trauma, is related to vasculitis, and often difficult to heal. Delayed healing is also due to impaired mobility which contributes to poor muscle pump. ${ }^{35}$ The oedema is often difficult to control. Ulceration of rheumatoid nodules is not common except at pressure points. ${ }^{40}$

\section{Trophic ulcers}

These ulcers may occur as a result of pressure or friction on areas which have become anaesthetic due to peripheral neuropathy. Sometimes they may be associated with underlying vascular abnormalities-for example, diabetes causing small vessel disease. ${ }^{35}$

\section{Ulceration due to dermatitis artefacta}

Ulceration secondary to artefact may be difficult to diagnose. Clinical suspicion might be raised by the following: unusual appearance, unusual site, after trauma at work with possible compensation issues, angulate shape or the apparent indifference of the patient to their ulcer and its implication to their life. ${ }^{26}$ If the ulcer tends to come and go, a skin biopsy may be necessary to show up "out-side-in" damage, that is, disproportionate damage to the epidermis compared with the dermis. ${ }^{26}$

\section{Pyoderma gangrenosum}

Pyoderma gangrenosum is a relatively common destructive non-infective ulceration of the skin with sloughy base and ragged undermined edge. It may be associated with chronic conditions such as inflammatory bowel disease, inflammatory arthropathies, or myeloproliferative disorders. ${ }^{26} \mathrm{~A}$ skin biopsy may be helpful 
but the histological features of pyoderma gangrenosum are not diagnostic.

\section{Treatment of leg ulcers}

INITIAL ASSESSMENT

Assessment of a patient with leg ulcer consists of the following:

- Comprehensive clinical history and physical examination in order to determine the aetiology of the ulcer.

- Doppler measurement of the pressure at the ankle (dorsalis pedis or posterior tibial artery) and brachial artery to determine ankle:brachial pressure index (if $<0.8=$ presence of arterial insufficiency, if $>1.0=$ venous insufficiency, and if $<0.5=$ need for urgent refferal to a vascular surgeon).

- The wound size and shape must be documented either by measuring the length and width of the ulcer by tracing onto an acetate sheet or by photographic record.

- The ulcer should be swabbed for microbiology.

- Full blood count, random blood sugar, chemical profile, and plasma viscosity should be done.

- Ulcers of unusual appearance should be biopsied.

- Deep ulcers should have plain radiography of the affected areas and computed tomography, magnetic resonance imaging, etc to exclude osteomyelitis, especially in chronic non-healing ulcers.

- Patch tests may be indicated if there is an extensive eczema or local allergy.

SPECIFIC TREATMENT

Primary dressing depends on the conditions of the ulcer base. Simple non-adherent gauze should be used for shallow, non-exudating ulcer. ${ }^{35}$ Absorbent foam or alginate dressings should be used for exudating ulcers, and hydrocolloids reserved for sloughy, smelly ulcers. Hyaluronic acid dressing is often used for sloughy, necrotic ulcers.

It is often necessary to treat $S$ aureus or $S$ pyogenes (haemolytic streptococci) if signs of inflammation are present. Larval (maggot) therapy is now available for debriding resistant sloughy ulcers. ${ }^{41}$ Indications of biosurgery (larval therapy) include necrotic or sloughy wounds-for example, leg ulcers, unsuitability for surgical debridement, and/or ineffective previous treatment. ${ }^{414}$

Surrounding skin should be protected with simple water based emollients. Eczema may require treatment with potassium permanganate, and wet compress and topical corticosteroid. Topical antibiotics should be avoided, because they can sensitise the skin. ${ }^{35}$ The most important allergens in 1994-95 were fragrance mix, colophony, excipients wool alcohol, amerchol, neomycin, and gentamycin. The changing trends in contact allergens over the last 20 years may be explained by changes in the components of topical agents used for treatment. ${ }^{43}$ Vacuum assisted closure (VAC), a non-invasive negative pressure healing device, is a wound care technology for the new millennium. ${ }^{44}$ The technique entails placing an open cell foam into the wound, sealing the site with an adhesive drape, and applying subatmospheric pressure $(125 \mathrm{~mm} \mathrm{Hg}(16.7 \mathrm{kPa})$ below ambient) that is transmitted to the wound in a controlled manner. Blood flow levels increased about fourfold when $125 \mathrm{~mm} \mathrm{Hg}$ subatmospheric pressure was applied. ${ }^{45}$ The VAC device is used to provide evacuation of wound fluid, stimulation of granulation tissue, decrease in bacterial colonisation, improvement of local oxygenation and promotion of angiogenesis, thereby enhancing wound healing. ${ }^{4}$ The Food and Drug Administration has recently approved the VAC device for closure of chronic wounds. ${ }^{46}$ The preferential indications of the VAC device include leg ulcers, pressure sores, burns, wounds with skin defects, complications of surgical wounds, and delayed healing. ${ }^{47}$

SECONDARY DRESSING

Secondary dressing with different types of compression bandages ${ }^{48}$ (three layers, four layers of bandages, for example, Charing Cross method) is crucial to the healing of venous ulcers (these bandages must not be used if there is arterial insufficiency). ${ }^{49}$ Community based leg ulcer clinics with trained nurses using a four layer bandage is more effective than traditional home based treatment and this is cost effective..$^{50}$ A survey of the management of leg ulcers in primary care settings in Scotland revealed that compression bandages were routinely used by $64 \%$ of nurses. ${ }^{51}$

GENERAL MEASURES

These consist of avoidance of prolonged standing or sitting with the feet dependent. Periods of rest with the legs elevated ${ }^{1}$ and graded exercises to improve the leg muscles pump should be practised. Once the ulcer is healed, the patient should wear elastic support hosiery. ${ }^{35}$

The severity of the venous insufficiency and the type of lifestyle ultimately determine the type of hosiery. There are three categories of compression hosiery conforming to the British Standard Instituition standard ${ }^{525}$ : light pressure at ankle $(12 \mathrm{~mm} \mathrm{Hg} / 1.6 \mathrm{kPa})$; medium (20 $\mathrm{mm} \mathrm{Hg} / 2.7 \mathrm{kPa}$ ) and strong $(30 \mathrm{~mm} \mathrm{Hg} / 4.0$ $\mathrm{kPa}$ ). Light compression is mostly inadequate whereas strong compression is effective, but uncomfortable and difficult for many elderly people. European standard compression hosieries are increasingly used. There are four classes of compression: light compression at the ankle $(18.4-21.1 \mathrm{~mm} \mathrm{Hg} / 2.5-2.8 \mathrm{kPa})$; medium (25.2-32.3 mm Hg/3.3-4.3 kPa); strong (36.5-46.6 mm Hg/4.9-6.2 kPa); and very strong (>59 $\mathrm{mm} \mathrm{Hg} />7.9 \mathrm{kPa}$ ). Light compression hosiery is indicated for treating mild varicosis; medium compression for pronounced varicosis with oedema, after healing of minor leg ulcer and after thrombophlebitis; strong compression for late complications of constitutional or post-thrombotic venous insufficiency, atrophie blanche, dermatosclerosis and after healing of severe or recurrent ulcers; very strong for lymphoedema and elephantiasis. The ideal is "made to measure" for the patient and to receive assistance with dressing. There are many aids available - for example, 
Medivalet with short handles, Medi-Export valet with long handles, Medivalet with variable handles, Medi-Hospital valet with adjustable diameter, and Medi-Magnum valet, especially for larger stocking sizes. The dressing aid solves the often difficult problem of putting on compression hosiery.

Patients should stop smoking, if there is associated arterial disease. Factors causing delay in healing leg ulcers include poor control of leg oedema because of inadequate compression, unrecognised arterial disease, continued smoking, secondary infection ( $S$ aureus), anae$\mathrm{mia}$, and/or heart failure. Adequate analgesics should be prescribed if the leg ulcers are painful. ${ }^{35}$ The Cadexomer Iodine Study Group demonstrated that cadexomer iodine paste is an efficient, cost effective, and safe alternative to hydrocolloid dressing and paraffin gauze dressing for the treatment of venous leg ulcers. $^{54}$

INTERMITTENT PNEUMATIC COMPRESSION

Pneumatic compression device may be used for the relief of oedema. ${ }^{3155}$ It may promote healing in patients with venous ulcers ${ }^{31}$ and is also useful in the treatment of lymphoedema. It consists of a sleeve that fits over the leg, attached to a pump device with a variety of pneumatic pumps with different specifications being available..$^{56}$ The response usually depends upon the absolute pressure generated within the compression cycle and the sequence and duration of compression. ${ }^{57}$ This method of treatment is generally useful in difficult venous ulcers which have not responded to compressive dressings.

HYPERBARIC OXYGEN

Hyperbaric oxygen is of no value in treating venous stasis ulcers or ulcers due to incompetent perforators. ${ }^{58}$ However, 18 of 27 arterial ulcers healed in 6-21 days. The affected leg was covered by a disposable polythene bag through which oxygen flowed (15 litres/min, six hours/day, four days/week). Pressure was monitored and kept at $25-30 \mathrm{~mm} \mathrm{Hg}(3.3-4.0 \mathrm{kPa})$, using a $\mathrm{Y}$ tube connected to a sphygmomanometer. Interspersed periods of tissue hypoxia help to stimulate formation of granulation tissue, so that continuous oxygen therapy is not desirable. ${ }^{58}$ It is difficult to assess the value of the hyperbaric oxygen independently of the period of enforced rest in the chamber. ${ }^{35}$

OTHER MEASURES

Diuretics are widely used in general practice even for postural oedema, which are best relieved by elevation and/or compression. ${ }^{35}$ In the past, different types of dressing with Debrisan, DuoDerm, benzoyl peroxide, cholestyramine powder, etc were used with some success, but are historically redundant. Other drugs might be helpful-for example, oxpentifylline, ${ }^{59}$ venruton, ${ }^{60}$ etc, but to date there is no substantial evidence to support this. A proteolytic ointment such as Elase (a combination of DNAase and fibrinolysin) provides no long term benefit in reducing exudate, pain, erythema, necrotic tissue, or overall condition of chronic leg ulcers when compared with either of its two components or placebo. ${ }^{61}$

\section{Treatment of arterial ulcers}

The most important aim in the treatment of arterial ulcers is to increase the blood supply to the affected area. ${ }^{35}$ The patient must stop smoking and diabetes or hypertension should be well controlled. Regular graded exercises should be encouraged to promote development of collateral circulation. Pressure areas may be protected by sheepskin or a special cushion with bony prominences, for example heel, malleoli, etc, being the vulnerable areas for leg ulcers. The head of the patient's bed should be raised by $4-6$ inches to encourage gravity dependent arterial flow and the limbs should be kept warm. Regular use of analgesics should be encouraged for the relief of pain, but if rest pain or acute infection is present, the patient should be referred to a vascular surgeon. Arterial reconstruction surgery may be performed to salvage the limb. After angiographic studies, endarterectomy to remove the clot or atheromatous plaques and/or reconstruction to bypass occluded artery may be performed. ${ }^{29} \mathrm{Bal}-$ loon angioplasty may be the intervention of choice for ischaemic rest pain, ulceration, and gangrene of the leg. If angioplasty fails, femoropopliteal bypass graft may be tried. ${ }^{62}$ Cellulitis with or without lymphangitis needs to be treated with systemic antibiotics.

\section{Management of diabetic and neuropathic} ulcers

The following instructions should be given to the patient:

- Stop smoking

- Regularly inspect the legs/feet for scratch marks, blisters, etc

- Wash the feet with warm water daily followed by careful drying between the toes

- Apply emolients, for example, Vaseline on the dry skin but not between the toes

- Inspect shoes regularly

- Wear properly fitting shoes

- It is useful to see a chiropodist regularly

- Avoid sandals and pointed shoes which may lead to foot trauma

- Never walk bare footed

- See your doctor regularly if there is any injury or blister of the leg/feet

Neuropathic ulcers are most commonly seen in diabetic patients. In diabetics, the feet should be examined regularly for tinea, deformities, and onychogryphosis. It is important to remove crusted areas,and to inspect and probe the wounds to determine the depth and the extent of tissue destruction. ${ }^{63-65}$ In case of infection with cellulitis the wound should be cultured and debrided. ${ }^{66}$ Oral broad spectrum antibiotics should be started and changed according to the sensitivity results. If there is no significant improvement within 48 hours, the patient should be hospitalised. Bacteroides, coliforms, and streptococci are frequently cultured. Nonweight bearing is essential until healing is in progress. Insulin is usually required to ensure good diabetic control and broad spectrum intravenous antibiotics are indicated. ${ }^{67} \mathrm{Re}$ - 
cently, new growth factor gel and licenced skin grafting (Apligraf) may be useful in quick healing of the ulcers. ${ }^{68}{ }^{69}$ Recently, it was claimed that topically applied granulocyte-macrophage colony stimulating factor healed chronic leg ulcers of necrobiosis lipoidica diabeticorum and may be a valuable drug for chronic non-healing ulcers in patients with diabetes. ${ }^{70}$

Radiography of the affected areas-for example, spiral computed tomography and/or magnetic resonance imaging should be performed to exclude osteomyelitis and also air within the soft tissues should be looked for to confirm the presence of gas forming organisms. Radionucleide bone scan, gallium scan, and bone biopsy may be necessary to confirm a diagnosis of osteomyelitis.

Once infection is controlled a decision can be made as to whether the patient needs vascular surgical treatment. Biopsy should be done for chronic non-healing ulcers. Biopsy of the ulcer edge certainly seems to be a procedure which can be performed at no risk to the patient. It has been suggested that biopsy of the ulcers that have not improved after three months of treatment should be performed to exclude squamous cell carcinoma, basal cell carcinoma, or vasculitis. If squamous cell carcinoma is suspected, a wedge rather than a standard punch biopsy should be performed. ${ }^{71}$

\section{Systemic treatment}

ANTIBIOTICS

Bacteria from the wound can be variable, but $S$ aureus is a common pathogen together with Gram negative bacilli and other organisms. ${ }^{32} 72$ In the patients with venous ulcers, cultures from the wound swabs correlate with cultures from biopsy specimens. ${ }^{72}$ Systemic antibiotics in uncomplicated venous ulcers are often not useful unless cellulitis or sepsis intervenes.

\section{FIBRINOLYTICS}

It has been demonstated that the patients with lipodermatosclerosis have depressed fibrinolytic activity. ${ }^{63}$ Stanozolol, an anabolic steroid and fibrinolytic enhancing agent, was found to improve liposclerosis but not venous ulceration in 14 patients treated in a preliminary trial. ${ }^{64} \mathrm{~A}$ subsequent double blind crossover trial in 23 patients did not shown any significant difference between the group who used only elastic compression stockings and the group who also received stanozolol. ${ }^{65}$ To date, there are no convincing data that suggests any benefit from the use of stanozolol in patients with dermatosclerosis or leg ulcers.

\section{Vasodilators}

PROSTAGLANDINS

Prostaglandins PGE1 and PGI2 are potent vasodilators and also inhibit platelet aggregation. Initial uncontrolled trials suggest success of intravenous infusions of PGE1 and PGI2 in patients with severe peripheral vascular disease with ulceration. ${ }^{73} \mathrm{~A}$ subsequent large multicentre trial demonstrated no difference between the placebo and the treatment group. ${ }^{74}$ Therefore, it should not be prescribed as its role in treating leg ulcers is not evidence based.
CALCIUM CHANNEL BLOCKERS

Nifedipine is a potent vasodilator with its mode of action, believed to be due to increased blood flow in the leg and foot in peripheral vascular disease. But the results of its use in the trials are conflicting. ${ }^{75} 76$ To date there is no convincing evidence of its value in the healing of leg ulcers due to peripheral arterial insuffiency. Therefore, from a practical point of view, it is usually not recommended.

\section{Serotonin antagonists}

Ketanserin, a serotonin antagonist, reduces peripheral vascular resistance and may improve peripheral haemodynamics in patients with intermittent claudication. ${ }^{41}$ Initial trials with ketanserin in treating patients with impending gangrene and peripheral ulceration are promising, ${ }^{42}$ but further data are necessary. Topical 2\% ketanserin ointment appears to improve granulation tissue formation in skin ulcers. ${ }^{77}$ In practice, it is hardly used to treat leg ulcers.

\section{Skin grafting}

PINCH GRAFTS

The simple type of split thickness skin grafts are safe and easy to perform. These procedures are particularly advisable in patients with multiple medical problems, taking drugs interfering with the healing of leg ulcers. It can be performed as an outpatient basis and in primary care. $^{78}$

SPLIT THICKNESS SKIN GRAFT

This method is used for large ulcers under general, spinal, or extensive local anaesthesia. These grafts are usually successful, but the grafts may contract after harvesting and need a large donor site, which may be slow to heal and cause a lot of pain. In grafting large leg ulcers, graft failure may occur because of build-up of exudate underneath the graft; this is best avoided by the use of a meshed graft. ${ }^{79}$

\section{Future trends in leg ulcer treatment}

ORAL ZINC TREATMENT

To determine whether oral zinc treatment was useful for venous leg ulcer, the search strategy of the Cochrane Wounds Group was used to identify the relevant randomised controlled trials. There were six such trials, which were small double blind, randomised, median size 33 (range $10-40$ patients). At present there is no evidence to support the use of oral zinc in the treatment of patients with leg ulcers due to venous or arterial disease. ${ }^{80}$ There is limited evidence that zinc may be beneficial in the treatment of venous leg ulcers when there is a low serum zinc but recommendations for the dose and duration of treatment cannot be made on the available information. ${ }^{81}$

\section{ORAL ASPIRIN}

Randomised trial of oral aspirin for chronic venous leg ulcer revealed reduction in ulcer surface area which was significantly better in the aspirin treated group at two months and four months compared with that in the placebo group. ${ }^{82}$ 
ULTRASOUND FOR CUTANEOUS WOUND HEALING Five controlled trials from the Cochrane Cutaneous Wound Healing Group demonstrated that low dose ultrasound is an effective complementary therapy for wound healing. Further experimental and clinical investigations should test its effectiveness more rigorously and elucidate the mechanisms that might be involved..$^{83} 84$

LASER THERAPY FOR THE TREATMENT OF VENOUS LEG ULCERS

To assess the effectiveness of low level laser therapy in the treatment of venous leg ulcers the Cochrane Wounds Group search strategy identified four eligible randomised controlled trials which demonstrated no evidence of any benefit associated with low level therapy on venous leg ulcer healing. One small study suggests that a combination of $\mathrm{HeNe}$ laser therapy and infrared light may promote the healing of venous ulcers, however more research is needed. ${ }^{85}$

\section{Compression treatment of leg ulcers: a systematic review}

To estimate the clinical and cost effectiveness of compression systems for treating venous leg ulcers, 19 electronic databases including Medline, CINAHL, Embase, relevant journals, and conference proceedings included 24 randomised controlled trials which demonstrated that compression systems improve healing of venous leg ulcers and should be routinely used in uncomplicated venous ulcers. High compression is more effective than low compression, ${ }^{49}$ but should only be used in the absence of significant arterial disease. There are no clear differences in the effectiveness of different types of compression systems (multilayer and short stretch bandages and Unna's boot) have been shown. Intermittent pneumatic compression appears to be a useful adjunct to bandaging. Rather than advocate one particular system, the increased use of any correctly applied high compression treatment should be performed. ${ }^{86}$ Compression bandages and stockings in the treatment of venous leg ulcers as reviewed by Cochrane Wounds Review Group, ${ }^{87}$ demonstrated that multilayer high compression bandages were significantly more effective than a single layer bandage. The direct comparisons of the healing rates were described in the two observational studies as $40 \%$ (of leg ulcers) in 12 weeks $^{88}$ and $42 \%$ (of limbs) of people attending a leg ulcer clinic. ${ }^{89}$ The limitations for use of four layer bandaging in a community clinic include the fact that some people are unable to leave their home due to immobility and cannot tolerate or do not like the treatment. ${ }^{90}$

\section{Cultured epidermal grafting}

AUTOGRAFT

The treatment of venous stasis ulcer can be done by the use of cultured epidermal cells (keratinocytes) as a skin graft. Keratinocyte layers cultured from the patient's own skin (autografts) have been successfully used for several years in the USA and Europe to cover large burn wounds. ${ }^{91}$ Other investigaters have used cultured autografts for chronic leg ulcers. ${ }^{92}$ One group reported healing of chronic leg ulcers within 35 days of application of cultured epithelial autografts. ${ }^{82}$

\section{ALLOGRAFTS}

Cultured epidermal allografts can be used in enhancing the healing rate of chronic leg ulcers. Previous trials have demonstrated that more than two thirds of chronic ulcers healed completely within eight weeks of grafting with a mean healing time of 3.3 weeks. ${ }^{93}{ }^{94}$ However cultured allografts should be reserved for the treatment of non-healing leg ulcers as cultivation procedure is very complex, labour intensive, and expensive.

\section{Apligraf: a biomaterial for wound healing/human skin equivalent ${ }^{68}$} Apligraf (Organogenesis, Canton, MA; Novartis, East Hanover, NJ, USA) is a new tissue engineered skin product cultured from human dermal fibroblasts and keratinocytes. Histologically it resembles a simplified version of skin. When applied, Apligraf seems to react to factors in the wound and may interact with the patient's own cells to stimulate the production of growth factors. It is being extensively studied in diabetic ulcers, clean excision wounds, and burns. ${ }^{95}$ Human skin equivalent appeared to promote wound healing in three ways: (1) apparent graft "take", (2) temporary wound closure, and (3) stimulation of host healing by acting as a biological dressing. The efficacy of human skin equivalent suggests that it will prove useful for promoting the healing of venous ulcers. ${ }^{69}$

\section{Electrical stimulation}

Electrical stimulation has been demonstrated to enhance wound healing. ${ }^{96}{ }^{97}$ The mechanism by which healing occurs remains unknown. They may include inhibition of bacterial growth, effects on fibroblasts motility, or increased expression of transforming growth factor- $\beta$ on fibroblasts. ${ }^{98} 99$

\section{Growth factors}

In animal models epidermal growth factor promotes granulation tissue formation and wound healing. A variety of growth factors - for example, tumour necrosis factors, fibroblast growth factor, transforming growth factors, $\alpha$ and $\beta$, epidermal growth factor, and platelet derived growth factors promote wound healing by angiogenic properties. ${ }^{95} 9798100$ Perhaps in the future combination of growth factors and compression dressings may have a role in the quick healing of the ulcers. Therapeutic angiogenesis may be one of the treatment strategies in the future.

\section{Conclusion}

Leg ulcers seem to have a cycle of healing followed by reulceration and rehealing. Recurrence rates of venous ulcers after treatment are high. ${ }^{98}$ Once the leg ulcer is healed careful skin care, continuous vigilance, and strict use of compression hosiery must be emphasised. 


\section{Key points}

- Treatment with compression bandages (three or four layers) hastens the healing of venous leg ulcers compared with no compression

- High compression is more effective than low compression provided there is no arterial insufficiency

- Intermittent pneumatic compression is a useful adjunct to compression bandaging

- Cultured epidermal autograft or allograft may be useful for chronic mixed ulcers

We thank the staff of the day hospital, especially Sue Walsh Pamela Sarkar, and the junior medical staff of City Hospital NHS Trust for their help in preparing the manuscript.

1 Logan R. Common skin conditions of the shins and feet. Medicine (International) 1997;25:26-7.

2 Johnson ML. Prevalence, morbidity and cost of dermatological diseases. F Invest Dermatol 1979;75:395-401.

3 Callum MJ, Ruckley CV, Harper DR, et al. Chronic ulceration of the leg: extent of the problem and provision of care BMF 1985;290:1855-6.

4 Biland L, Widmer LK. Varicose veins and chronic venous insuffiency. Acta Chir Scand 1988;544(suppl):9-11.

5 Hannson C, Anderson E, Swanbeck G. Leg ulcer epidemiology in Gothenburg. Acta Chir Scand 1988;544(suppl):126.

6 Dale JJ, Callam MJ, Ruckley CV, et al. Chronic ulcers of the leg: a study of prevalence in a Scottish community. Health leg: a study of prevalence in
Bull (Edinb) 1983;41:310-4.

7 Cornwall JV, Dore CJ, Lewis JD. Leg ulcers; epidemiology and aetiology. Br F Surg 1986;73:693-6.

8 Hallbook T. Leg ulcer epidemiology. Acta Chir Scand 1988; 544(suppl): $17-20$.

9 Callam MJ, Harper DY, Dale JJ, et al. Chronic ulcer of the leg: clinical history. BMF 1987;294:1389-91.

10 Moffatt CJ, Franks PJ. A prerequisite underlying the reatment programme: risk factors associated with venous disease. Professional Nurse 1994;9:637-42.

11 Morrison M, Moffatt C. A colour guide to the assessment and management of leg ulcers. London: Times Mirror International, 1994

12 Young JR. Differential diagnosis of leg ulcers. Cardiovascular Clinics 1983;13:171-93.

13 Anning JT. Leg ulcers: their cause and treatment. London: Churchill Livingstone, 1954.

14 Adams EF. The genuine works of Hippocrates. London: Sydenham Press, 1949.

15 Browse NL, Burnand KG. The cause of venous ulceration. Lancet 1982;ii:243-5.

16 Gay J. On varicose diseases of the lower extremities. The Lettsomian Lectures of 1867. London: Churchill Livingstone, 1968 17 Homans J. The aetiology and treatment of varicose ulcer of the leg. Surg Gynecol Obstet 1917;24:300-11

18 Herouy Y, Nockowski P, Schopf E, et al. Lipodermatosclerosis and the significance of proteolytic remodelling in the pathogenesis of venous ulceration. International fournal of Molecular Medicine 1999;3:511-5.

19 Herouy Y, May AE, Pornschlegel G, et al. Lipodermatosclerosis is characterized by elevated expression and activation of matrix metalloproteinases: implications for venous ulcer formation. 7 Invest Dermatol 1998;111:822-7.

20 Nwomeh BC, Liang HX, Cohen IK, et al. MMP-8 is the predominant collagenase in healing wounds and nonhealing ulcers. F Surg Res 1999;81:189-95.

21 Jude EB, BoultonAJ, Ferguson MW, et al. The role of nitric oxide synthase isoforms and arginase in the pathogenesis of
diabetic foot ulcers: possible modulatory effects by transdiabetic foot ulcers: possible modulatory effects by trans-
forming growth factor beta 1. Diabetologica 1999;42:74857.

22 Loots MA, Lamme EN, Zeegelaar J, et al. Differences in cellular infiltrate and extracellular matrix of chronic diabetic and venous ulcers versus acute wounds. $\mathcal{F}$ Invest Dermato 1998;111:850-7.

23 Hahn J, Junger M, Friedrich B, et al. Cutaneous inflammation limited to the region of the ulcer in chronic venous insufficiency. Vasa 1997;26:277-81.

24 Burnand KG, Whimster IW, Clemenson G. The relationship between the number of capillaries in the skin of the venous ulcer bearing area of the lower leg and the fall in foot vein pressure during exercise. Br F Surg 1981;68:297-300.

25 Burnand KG, Clemenson G, Gaunt J, et al. The effect of sustained venous hypertension in the skin capillaries of the canine hind limb. Br F Surg 1981;69:41-4.

26 Bull R. Common causes of leg ulceration. Hos Med Nov 1998;59:11.

27 Burnand KG, Whimster I, Naidoo A, et al. Pericapillary fibrin deposition in the ulcer bearing of the skin of the lower
limb:the cause of lipodermatosclerosis and venous ulceralimb:the cause of lipodermatos
tion. BMF 1982;285:1071-2.
28 Hopkins NFG, Spinks TJ, Rhodes CG, et al. Positron emission tomography in venous ulceration and liposclerosis
study of regional tissue function. BMF 1983;286:333-6.

29 Van de Scheur M, Falanga V. Pericapillary fibrin cuffs in venous disease: a reappraisal. Dermatol Surg 1997;23:955-9.

30 Coleridge-Smith PD, Thomas P, Scurr JH, et al. Causes of venous ulceration: a new hypothesis. BMF 1988;296:1726-

31 Kolari PI, Pekanmaki K. Intermittent pneumatic compression in healing of venous ulcers (letter). Lancet 1986;ii: 1108 .

32 Falanga V, Eaglstein WH. The "trap" hypothesis of venous ulceration. Lancet 1993;341:1006-8.

33 Birgette Maessen-Visch M, Hamulyak K, Tazelaar DJ, et al. The prevalence of factor V Leiden mutation in patients with The prevalence of factor V Leiden mutation in patients with leg ulcers $41-4$.

34 Danielsen L, Westh H, Balselv E, et al. Pseudomonas aeruginosa exotoxin A antibodies in rapidly deteriorating chronic leg ulcers. Lancet 1996;347:265.

35 Champion RH, Burton JL, Burns DA, et al, eds. Rook, Wilkinson and Ebling's textbook of dermatology. 6th Ed. Oxford: Blackwell Scientific, 1998: 2257-75.

36 Jelinek JE. Cutaneous manifestations of diabetes mellitus. Int $\mathcal{F}$ Dermatol 1994;33:605-17.

37 Eckman JR. Leg ulcers in sickle cell disease. Hematol Oncol Clin North Am 1996;10:1333-44.

38 Angle B, Burton BK. Familial leg ulcers. Lancet 1998;351: 1031-2.

39 Peus D, Heit JA, Pittelkow MR. Activated protein C resistance caused by factor $\mathrm{V}$ gene mutation: common coagulation defect in chronic venous leg ulcers? $f$ Am Acad Dermatol 1997;36:616-20

40 Cream JJ. Cutaneous vasculitis. In: Ansell BM, Bacon PA, Lie JT, et al, eds. The vasculitides, science and practice. London: Chapman and Hall Medical, 1996: 294.

41 Thomas S, Jones M, Shulter S. All you need to know about maggots. Nursing Times 1996;92(46):63-78.

42 Evans H. A treatment of last resort. Nursing Times 1997;93(23):62-5.

43 Katsarou-Katsari A, Armenaka M, Katsenis $\mathrm{K}$, et al. Contact allergens in patients with leg ulcers. Fournal of the European Academy of Dermatology and Venereology 1998;11: $9-12$.

44 Kalailieff D. Vacuum-assisted closure: wound care technology for the new millennium. Perspectives 1998;22:28-9.

45 Morykwas MJ, Argenta LC, Shelton-Brown EI, et al. Vacuum-assisted closure: a new method for wound control and treatment: animal studies and basic foundation. Ann Plast Surg 1997;38:553-62.

46 Blackburn JH, Boemi L, Hall WW, et al. Negative-pressure dressings as a bolster for skin grafts. Ann Plast Surg 1998;40: $453-7$

47 Voinchet V, Magalon G. Vacuum-assisted closure. Wound healing by negative pressure. Ann de Chirurgie Plastique et Esthetique 1996;41:583-9.

48 Collins K, Morrell J, Peters J, et al. Variations in venous leg ulcer care in the community. British fournal of Community Nursing 1998;3:6-12.

49 Wertheim D, Melhuish J, Williams R, et al. Measurement of forces associated with compression therapy. Med Biol Eng Comput 1999;37:31-4.

50 Morrell CJ, Walters SJ, Dixon S, et al. Cost effectiveness of community leg ulcer clinics: randomised controlled trial. BMF 1998;316:1487-91.

51 Hickie S, Ross S, Bond C. A survey of the management of leg ulcers in primary care settings in Scotland. Fournal of Clinical Nursing 1998;7:45-50.

52 Compression hosiery for stasis disorders. Drug Ther Bull 1982;20:81-4.

53 Thomas S. Bandages and bandaging: the science behind the art. Care Science Practitioner 1990;8:61-2.

54 Hansson C. The effects of cadexomer iodine paste in the treatment of venous leg ulcers compared with hydrocolloid dressing and paraffin gauze dressing: Cadexomer Iodine Study Group. Int $\mathcal{F}$ Dermatol 1998;37:390-6.

55 Richmond DM, O'Donnell T, Zelikovski A. Sequential pneumatic compression for lymphoedema. Arch Surg 1985; 20:1116-9.

56 Zelikovski A, Deutsch A, Reiss A. The sequential pneumatic compression device in surgery for lymphedema of the limbs. 7 Cardiovasc Surg 1983;24:122-6.

57 Falanga V, Eaglstein WH. Wound healing: practical aspects. Progress in Dermatology 1988;22:1-9.

58 Heng MCY, Pilgrim JP, Beck FWJ. A simplified hyperbaric oxygen technique for leg ulcers. Arch Dermatol 1984;120: oxygen $640-5$.

59 Colgan MP, Dormandy JA, Jones PW, et al. Oxpentifylline treatment of venous ulcers of the leg. BMF 1990;300:927-9. 60 Belcaro C, Rulo A, Candiani C. Evaluation of the microcirculatory effects of venruton in patients with chronic venous hypertension. Vasa 1989;14:146-51

61 Falabella AF, Carson P, Eaglstein WH, et al. The safety and efficacy of a proteolytic ointment in the treatment of chronic ulcers of the lower extremity. F Am Acad Dermatol 1998;39: $737-40$

62 Keen G, Farndon J, eds. Operative surgery and management. 3rd Ed. Oxford: Butterworth-Heinemann, 1994: 558-63.

63 Gibbons GW. The diabetic foot: amputations and drainage of infection. I Vasc Surg 1987;5:791-3.

64 Hurley JJ, Ayer AI, Hershey FB, et al. Distal artertial construction:patency and limb salvage in diabetes. $\mathcal{F}$ Vasc Surg 1987;5:796-802 
65 Owen JA. How to treat the diabetic foot. Geriatrics 1982; March:57-69.

Successful methods of treating leg ulcers. tried and true, plus the novel and new. Postgrad Med tried and true, plus the novel

67 Gibbons GW, Eliopoulos GM. Infection of the diabetic foot. n: Kozak GP, ed. Management of diabetic foot problems. Philadelphia: WB Saunders, 1984: 97-103.

68 Fahey CB. Experience with a new human skin equivalent for healing venous leg ulcers. Fournal of Vascular Nursing 1998;16:11-5.

69 Alvarez OM, Fahey CB, Auletta MJ, et al. A novel treatmen for venous leg ulcers. F Foot Ankle Surg 1998;37:319-24.

70 Remes K, Ronnemaa T. Healing of chronic leg ulcers in diabetic necrobiosis lipoidica with local granulocytemacrophage colony stimulating factor treatment. $\mathcal{F}$ Diabetes Complications 1999;13:115-8.

71 Phillips TJ, Dover JS. Leg ulcers. F Am Acad Dermatol 1991; 25:965-87.

72 Skillman JJ. Arterial leg ulcers. In Rudolph R, Noe J, eds. Chronic problem wounds. Boston: Little Brown, 1983: $103-12$.

73 Lookingbill DP, Miller SH, Knowles RC. Bacteriology of chronic leg ulcer. Arch Dermatol 1978;114:1765-8.

74 Browse NL, Gray L, Jarrett PEM, et al. Blood and vein wall fibrinolytic activity in health and vascular disease. $B M F$ $1977 ; \mathbf{i}: 478-81$.

75 Browse NL, Jarrett PE, Moerland M, et al. Treatment of liposclerosis of the leg by fibrinolytic enhancement: a preliminary report. BMF 1977;ii:434-5.

76 Burnand KG, Clemenson G, Morland M, et al. Venous lipodermatosclerosis: treatment by fibrinolytic enhancement and elastic compression. BMF 1980;280:7-11.

77 Eklund AE, Eriksson G, Olsson AG. A controlled study showing significant short-term effect of prostagladin E1 in healing of ischaemic ulcers of the lower limb in man. Prostaglandins, Leukotrienes, and Medicine 1982;8:265-71.

78 Oien RF, Hansen BU, Hakansson A. Pinch grafting of leg ulcers in primary care. Acta Derm Venereol 1998;78:438-9.

79 Nappi JF, Falcone RE, Ruberg RL. Meshed grafts vs sheet skin grafts on a contaminated bed. Fournal of Dermatology skin grafts on a contaminated bed. Four

80 Wilkinson EA, Hawke CI. Does oral zinc aid the healing of Wilkinson EA, Hawke CI. Does oral zinc aid the healing of
chronic leg ulcers? A systematic literature review. Arch Derchronic leg ulcers? A syst

81 Wilkinson EAJ, Hawke CI. Oral zinc of venous leg ulcer treament. The Cochrane Library 1999; issue 1: 1-8

82 Layton AM, Ibbotson SH, Davies JA, et al. Randomised tria of oral aspirin for chronic venous leg ulcers. Lancet 1994;344:164-5.

83 Ernst E. Ultrasound for cutaneous wound healing. Phlebolgy $1995 ; \mathbf{1 0}: 2-4$
84 Johannsen F, Gam AN, Karlsmark T. Ultrasound therapy in chronic leg ulceration: a meta-analysis. Wound Repair Regenration 1998;6:121-6.

85 Flemming K, Cullum N. Laser therapy for the treatment of venous leg ulcers. The Cochrane Library 1999; issue 1: 1-9.

86 Fletcher A, Cullum N, Sheldon TA, et al. A systematic review of compression treatment for venous leg ulcers. BMF 1997;315:576-580.

87 Cullum N, Fletcher AW, et al. Compression bandages and stockings in the treatment of venous leg ulcers. The Cochrane Library, 1999; issue 1: 1-10.

88 Thomson B, Hooper P, Powell R, et al. Four-layer bandaging and healing rates of venous leg ulcers. Fournal of Wound Care 1996;5:212-16.

89 Simon DA, Freak L, Kinsella A, et al. Community leg ulcer clinics: a comparative study in two health authorities. BMF 1996;312:1648-51

90 Brereton L, Morrell J, Collins K, et al. Patients' tolerance of leg ulcer treatments. British Fournal of Community Health Nursing 1997;2:427-35.

91 Philips T. Cultured skin grafts: past, present, future. Arch Dermatol 1988:124:1035-8.

92 Villeneuve P, Hafner J, Prenosil JE, et al. A novel culturing and grafting system for the treatment of leg ulcers. Br f Dermatol 1998;138:849-51.

93 Philips T, Gilchrest BA. Cultured allogenic keratinocyte grafts in the management of wound healing: prognostic factors. Fournal of Dermatology and Surgical Oncology 1989;15: 1169-76.

94 Philips TJ, Kehinde O, Green $\mathrm{H}$, et al Treatment of skin ulcers with cultured epidermal allografts. $\mathcal{F} \mathrm{Am}$ Acad Dermatol 1989;21:191-9.

95 Sabolinski ML, Alvarez O, Auletta M, et al. Cultured skin as a "smart material" for healing wounds: experience in venous ulcers. Biomaterials 1996;17:311-20.

96 Gault WR, Gatens PF. Use of low intensity direct current in management of ischaemic skin ulcers. Phys Ther 1976;56: 265-9.

97 Rowley BA, Mckenna JM, Chase GR, et al. The influence of electrical current on an infecting microorganism in wounds. Ann N Y Acad Sci 1974;238:543-52.

98 Barranco SD, Spardaro JA, Berger TJ, et al. In vitro effects of a weak direct current on Staphylococcus aureus. Clin Orthop Rel Res 1974;100:250-5.

99 Erickson CA, Nuccitelli R. Embryonic fibriblast motility and orientation can be influenced by physiological electrical fields. F Cell Biol 1984;98:296-307.

100 Carley PJ, Wainpel SF. Electrotherapy for acceleration of wound healing: low density direct current. Arch Phys Med Rehabil 1985;66:443-6. 